\title{
Effect of BMPRIB gene silencing by siRNA on apoptosis and steroidogenesis of porcine granulosa cells
}

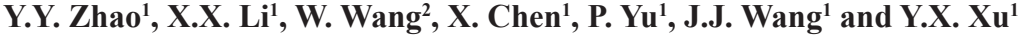 \\ ${ }^{1}$ College of Animal Science and Technology, Nanjing Agricultural University, \\ Nanjing, China \\ ${ }^{2}$ Harbin Veterinary Research Institute, Chinese Academy of Agricultural Science, \\ Harbin, China \\ Corresponding authors: Y.X. Xu / Y.Y. Zhao \\ E-mail: xuyinxue@njau.edu.cn / zhaoyongyan@163.com
}

Genet. Mol. Res. 13 (4): 9964-9975 (2014)

Received November 30, 2012

Accepted February 5, 2013

Published November 28, 2014

DOI http://dx.doi.org/10.4238/2014.November.28.1

\begin{abstract}
Bone morphogenetic proteins (BMPs) are the key factors in maintaining cell growth and differentiation in ovaries. BMPs initiate signaling by assembling BMP receptors and activating Smads, which in turn alter the expression of target genes. However, little is known about the effect of the deletion of the Bone morphogenetic protein receptor type IB (BMPRIB) on porcine granulosa cell (GCs). The objective of this study was to determine the effects of $B M P R I B$ gene silencing, by small interfering RNA (siRNA), on the apoptosis and steroidogenesis of porcine GCs, and the expression of cell cycle-related and apoptosis-related genes. Results indicate that the $B M P R I B$ siRNA caused specific inhibition of $B M P R I B$ mRNA expression after transfection. Knockdown of the $B M P R I B$ gene significantly inhibited porcine GCs proliferation and estradiol production, while inducing apoptosis of porcine GCs. Additionally, the declined expression of the BMPRIB gene changed the expressions of CylinD2, Cdk2, Bcl-2, and Cyp19a1. These
\end{abstract}


findings provide an important role of BMPRIB in the regulation of apoptosis and steroidogenesis of porcine GCs.

Key words: $B M P R I B$; Porcine granulosa cells; siRNA; Apoptosis; Steroidogenesis

\section{INTRODUCTION}

Bone morphogenetic protein (BMP), a group of dimeric peptides, belongs to the transforming grow th factor beta (TGF- $\beta$ ) superfamily and exhibits broad spectra of biological activities in various tissues. Recently, research on reproduction found the coordinate spatiotemporal expression patterns of the key members of the BMP system (ligands, receptors, and signaling molecules) throughout the genital system (Erickson and Shimasaki, 2003). The BMP signaling pathway plays a crucial role in female fertility in mammals by regulating steroidogenesis and mitogenesis in granulosa cells (GCs) (Shimasaki et al., 2003, 2004). BMP2 , BMP-4, BMP-6, BMP-7, and BMP-15 can inhibit the secretion of 3- $\beta$-hydroxysteroid dehydrogenase and progesterone, and the expression of the follicle-stimulating hormone (FSH) receptor in different cells respectively (Shimasaki et al., 1999; Lee et al., 2001; Otsuka et al., 2001a,b; Nilsson and Skinner, 2003; Brankin et al., 2005; Miyoshi et al., 2006); in addition, BMP-7 was quite potent in promoting primordial follicles into primary and secondary follicles (Lee et al., 2001).

To achieve the biological functions, BMPs first need to combine with the corresponding membrane receptors. The BMPRIB gene belongs to the type I receptors, which are critical in the transforming growth factor-beta (TGF- $\beta$ ) signaling from the cell membrane to the nucleus (Heldin et al., 1997; Shi and Massague, 2003; Lavery et al., 2008). Plenty of studies have found that the BMPRIB gene plays a crucial role not only in the differentiation and apoptosis of osteoblasts but also in the proliferation and differentiation of granulosa cells, as well as in the development of follicles and in the promotion of ovulation rate. Researches have demonstrated that BMPRIB is present in both granulosa cells and oocytes, respectively, in sheep and pigs (Wilson et al., 2001; Quinn et al., 2004). Souza et al. (2001) and Wilson et al. (2001) found that partial inactivation of the BMPRIB gene caused by gene mutation leads to an increase of ovulation rate and multiple births. Recent studies found irregular estrous cycles and impaired pseudopregnancy responses in BMPRIB-deficient mice, and furthermore, the oocytes failed to be fertilized in vivo (Souza et al., 2001). Conditional knockout of BMPRIA leads to sub-fertilization with reduced spontaneous ovulation in mice, and moreover, doubleknockout of BMPRIA and BMPRIB represses the development of follicles, even provoking the tumorigenesis of the ovary (Edson et al., 2010). Additionally, researchers have demonstrated the upregulation of BMPRIB by the follicle-stimulating hormone in the human granulosa KGN cell line (Miyoshi et al., 2006). Taken together, these results imply that BMPRIB plays a crucial role in female fertility in mammals. However, the effectiveness of BMPRIB with regard to the productivity of pigs is rarely reported. To further study this, we measured the expression of BMPRIB in different-sized follicles of commodity pigs. Then, we used small interfering RNA (siRNA) interference to suppress the BMPRIB gene expression in order to investigate the effects of BMPRIB siRNA transfection on the apoptosis and proliferation steroidogenesis of porcine granulosa cells (pGCs). 


\section{MATERIAL AND METHODS}

\section{Porcine ovary collection and follicle selection}

Porcine ovaries were obtained from a local slaughterhouse and transported to the laboratory at $37^{\circ} \mathrm{C}$ in saline containing gentamicin and amphotericin. The ovaries were washed three times with pre-warmed phosphate-buffered saline (PBS) supplemented with gentamicin and amphotericin. Follicles were sorted to three grades according to their size in diameter: small follicles $(<3 \mathrm{~mm})$, middle follicles (between 3 and $6 \mathrm{~mm}$ ), and dominant follicles $(>6 \mathrm{~mm})$. Cells from these follicle groups were pooled, and six independent follicles in each pool were used for gene expression studies, each performed in triplicate samples. The tissue samples were frozen at $-80^{\circ} \mathrm{C}$.

\section{Isolation and culture of GCs}

GCs were collected from follicles ( 3 to $6 \mathrm{~mm}$ in diameter) by aspiration using a syringe with $20 \mathrm{G}$ needle and filtered through a $100-\mu \mathrm{m}$ sterile steel mesh to remove the cumulusoocytes complexes. The cells were centrifuged for $5 \mathrm{~min}$ at $800 \mathrm{xg}$ at room temperature and washed adequately twice with DMEM/F12 medium (Dulbecco's modified Eagle's medium/ Ham's nutrient mixture F12; Shanghai Invitrogen Biotechnology Co., Ltd., China). GCs were cultured as described previously (Picton et al., 1999). The cells were counted in a hemocytometer, and the viability was determined with trypan blue staining. Then, GCs were seeded in 6-well culture plates (Costar; Corning Inc., NY, USA) at a density of $10^{6}$ cells/ $\mathrm{mL}$ with $2 \mathrm{~mL}$ DMEM/F 12 medium containing 10\% (v/v) fetal calf serum (FCS; Minhai Co., Lanzhou, China) and $5 \mu \mathrm{L} / \mathrm{mL}$ gentamicin and $10 \mu \mathrm{L} / \mathrm{mL}$ amphotericin. The cells were cultured for $24 \mathrm{~h}$ at $37^{\circ} \mathrm{C}$ in a $5 \% \mathrm{CO}_{2}$ atmosphere and then the wells were washed with PBS to remove unattached cells. Exponentially growing cells were used for the experiments.

\section{Design and transfection of siRNAs}

Three pairs of siRNAs targeting BMPRIB were designed according to the BMPRIB sequence in GenBank (NM_001039745). Three pairs of oligonucleotides corresponding to $B M$ $P R I B$ cDNA at the start positions 547,986 , and 1130 bp were designed. Three siRNA sequences that cover different regions of the BMPRIB coding sequence without homology to the non$B M P R I B$ sequence were custom-synthesized by Genepharm (Shanghai, China). In addition, a nonspecific scrambled siRNA duplex labeled with FAM (Genepharm) served as a control to determine optimal conditions for siRNA transfection. The BMPRIB small RNAi was named BMPRIB-siRNA, and the nonsense sequence to BMPRIB was named NC-siRNA (Table 1).

The three pairs of siRNAs were tested at different concentrations for each knockdown experiment, with the results presented here being obtained from the single most effective siRNA. Granulosa cell cultures were transfected with BMPRIB-siRNA or NC-siRNA using Lipofectamine ${ }^{\mathrm{TM}}$ RNAiMAX Reagent (Invitrogen Biotechnology Co., Ltd, Shanghai, China). Briefly, RNAi duplex, Lipofectamine ${ }^{\mathrm{TM}}$ RNAiMAX, and $250 \mu \mathrm{L}$ DMEM/F 12 medium were combined and incubated for $20 \mathrm{~min}$ at room temperature. The transfection complex was added to the cells and incubated for $6 \mathrm{~h}$ at $37^{\circ} \mathrm{C}$ in $100 \%$ relatively humidified atmosphere of $5 \% \mathrm{CO}_{2}$ 
(v/v) in air. The culture medium was changed to DMEM/F 12 with antibiotic supplement and FCS. Subsequently, the cells were incubated for another $48 \mathrm{~h}$ prior to assay.

\begin{tabular}{ll} 
Table 1. Sequences for porcine BMPRIB siRNA. & \\
\hline Name & Primer sequence \\
\hline BMPRIB siRNA-547 & Sense: GCACAGAUGGAUAUUGUUUTT \\
BMPRIB siRNA-986 & Anti: AAACAAUAUCCAUCUGUGCTT \\
BMPRIB siRNA-1130 & Sense: GCUGGUCCAGAGGACUAUATT \\
Negative Control & Anti: UAUAGUCCUCUGGACCAGCTT \\
& Sense: CCGAGAGACAGAAAUAUAUTT \\
& Anti: AUAUAUUUCUGUCUCUCGGTT \\
\hline
\end{tabular}

\section{RNA extraction and cDNA synthesis}

The total RNA was extracted from GCs and follicles using Trizol regent (Invitrogen), according to manufacturer instructions. Before the total RNA was extracted from follicles, the liquid in the follicles was abscised by centrifugation. The concentration and purity of RNA were detected by measuring the optical density (OD) at wavelengths of 260 and $280 \mathrm{~nm}$ using a standard spectrophotometer. The $\mathrm{OD}_{260} / \mathrm{OD}_{280}$ ratios ranged from 1.8 to 2.0 for all the samples.

For reverse transcription, $500 \mathrm{ng}$ total RNA, $1.84 \mu \mathrm{L} 500 \mu \mathrm{g} / \mathrm{mL}$ oligo $(\mathrm{dT})_{12-18}$, and 4 $\mu \mathrm{L} 2.5 \mathrm{mM}$ dNTP were added to DEPC-water to a final volume of $12 \mu \mathrm{L}$, and the mixture was incubated at $65^{\circ} \mathrm{C}$ for $5 \mathrm{~min}$. Then, $4 \mu \mathrm{L} 5 \mathrm{X}$ first-stand synthesis buffer, $2 \mu \mathrm{L} 0.1 \mathrm{M}$ DTT, and 1 $\mu \mathrm{L}$ Rasin inhibitor (Invitrogen) were added into the solution, prepared as described above, to a final volume of $19 \mu \mathrm{L}$ and left to incubate at $37^{\circ} \mathrm{C}$ for $2 \mathrm{~min}$. Finally, $1 \mu \mathrm{L}$ Moloney murine leukemia virus reverse transcriptase was added to the solution to a final volume of $20 \mu \mathrm{L}$, and after a 50 -min incubation at $37^{\circ} \mathrm{C}$, the enzyme was inactivated by incubation at $70^{\circ} \mathrm{C}$ for $15 \mathrm{~min}$.

\section{Quantitative real-time PCR}

The gene-specific primers were designed on the basis of porcine mRNA sequences (Table 2) and synthesized by Invitrogen. Briefly, the target genes and the housekeeping glyceraldehyde-3-phosphate dehydrogenase gene were amplified using the SYBR Green Kit (Roche, Germany) with an ABI 7300 system. The amplification and quantification of products were performed in a reaction of $20 \mathrm{~mL}$ for 40 cycles. To obtain the relative concentration of mRNA, the $2^{-\Delta \Delta \mathrm{Ct}}$ method was used (Livak and Schmittgen, 2001).

\section{Measurement of cell activity by MTT assay}

GCs were seeded in 96-well culture plates at a density of $3 \times 10^{4}$ to $5 \times 10^{4}$ per well for cell transfection. Subsequently, after $36 \mathrm{~h}$, the activity of GCs was measured using the 3-(4,5-dimethylthiazol-2-yl)-2,5-diphenyltetrazolium bromide (MTT) Kit (KeyGEN Biotechnology Co., Ltd., Nanjing, China) according to manufacturer instructions. The $\mathrm{OD}_{550}$ was detected by an enzyme-linked immunosorbent assay reader (Bio-TEK Instruments, USA). 
Table 2. Details of primers for target gene amplification.

\begin{tabular}{|c|c|c|c|}
\hline Primer & Primer sequence & Product size (bp) & Annealing temperature $\left({ }^{\circ} \mathrm{C}\right)$ \\
\hline \multirow[t]{2}{*}{ BMPRIB } & Forward: CATTTTGGGCTTCATTGCT & & \\
\hline & Reverse: GGGTGGTGGACTTCAGGTA & 195 & 62 \\
\hline \multirow[t]{2}{*}{$\mathrm{Bcl}-2$} & Forward: TTCTTTGAGTTCGGTGGGG & & \\
\hline & Reverse: CCAGGAGAAATCAAATAGAGGC & 116 & 58 \\
\hline \multirow[t]{2}{*}{ Bax } & Forward: CCGAAATGTTTGCTGACG & & \\
\hline & Reverse : AGCCGATCTCGAAGGAAGT & 154 & 58 \\
\hline \multirow[t]{2}{*}{ CyclinD2 } & Forward: TTACCTGGACCGCTTCTTG & & \\
\hline & Reverse: GAGGCTTGATGGAGTTGTCG & 155 & 54.0 \\
\hline \multirow[t]{2}{*}{ Cdk2 } & Forward: AAACAAGTTGACGGGAGA & & \\
\hline & Reverse: GTGAGAATGGCAGAAAGC & 298 & 56.0 \\
\hline \multirow[t]{2}{*}{ Сyp19a1 } & Forward: GCTGCTCATTGGCTTAC & & \\
\hline & Reverse: TCCACCTATCCAGACCC & 187 & 60.5 \\
\hline \multirow[t]{2}{*}{ Cyp11a1 } & Forward: AGACACTGAGACTCCACCCCA & & \\
\hline & Reverse: GACGGCCACTTGTACCAATGT & 110 & 69.5 \\
\hline \multirow{2}{*}{ GAPDH } & Forward: GGACT CATGACCACG GTCCAT & & \\
\hline & Reverse: TCAGATCCAC AACCG ACACG T & 220 & 58 \\
\hline
\end{tabular}

\section{Measurement of apoptosis by annexin-V/propidium iodide double-staining flow cytometry}

GCs were cultured for $36 \mathrm{~h}$ and harvested into a $1.5 \mathrm{~mL}$ centrifuge tube using $0.25 \%$ trypsin (without EDTA) (Gibco, USA) and washed twice with PBS. Then, $5 \mu \mathrm{L}$ annexin Vrhodamine isothiocyanate plus propidium iodide was added to the tube, and the cells were incubated for $15 \mathrm{~min}$ at room temperature.

\section{Statistical analysis}

All results are reported as the mean \pm standard error (SE) from at least three separate experiments, each performed with triplicate samples. Data were analyzed by one-way analysis of variance, followed by the Fisher least significant difference test for multiple comparisons, using the SPSS 18.0 software. Differences were considered to be statistically significant at the 95\% confidence level $(\mathrm{P}<0.05)$.

\section{RESULTS}

\section{Expression of BMPRIB in follicles of different sizes of commercial pigs}

The expression of BMPRIB in follicles of different sizes of commercial pigs was investigated by quantitative real-time PCR. BMPRIB mRNA levels were increased with the follicular development. The $B M P R I B$ mRNA levels in large follicles were significantly higher than those in medium follicles and small follicles by 1.19-fold and 1.87-fold, respectively $(\mathrm{P}<0.05)$ (Figure 1).

\section{Effect of siRNA on BMPRIB expression}

Three siRNA duplexes were transfected into cells, and $48 \mathrm{~h}$ later, RT-PCR analysis confirmed that the three BMPRIB-siRNAs had reduced the amounts of endogenous BMPRIB 
mRNA levels. The BMPRIB-siRNA-1130 was the optimal site for BMPRIB knockdown. The expression of $B M P R I B$ mRNA was inhibited after transfection with BMPRIB-siRNA-1130, with the $B M P R I B$ transcript level being reduced by approximately $65 \%$ compared with that in the control cultures (blank and NC-siRNA) (Figure 2).

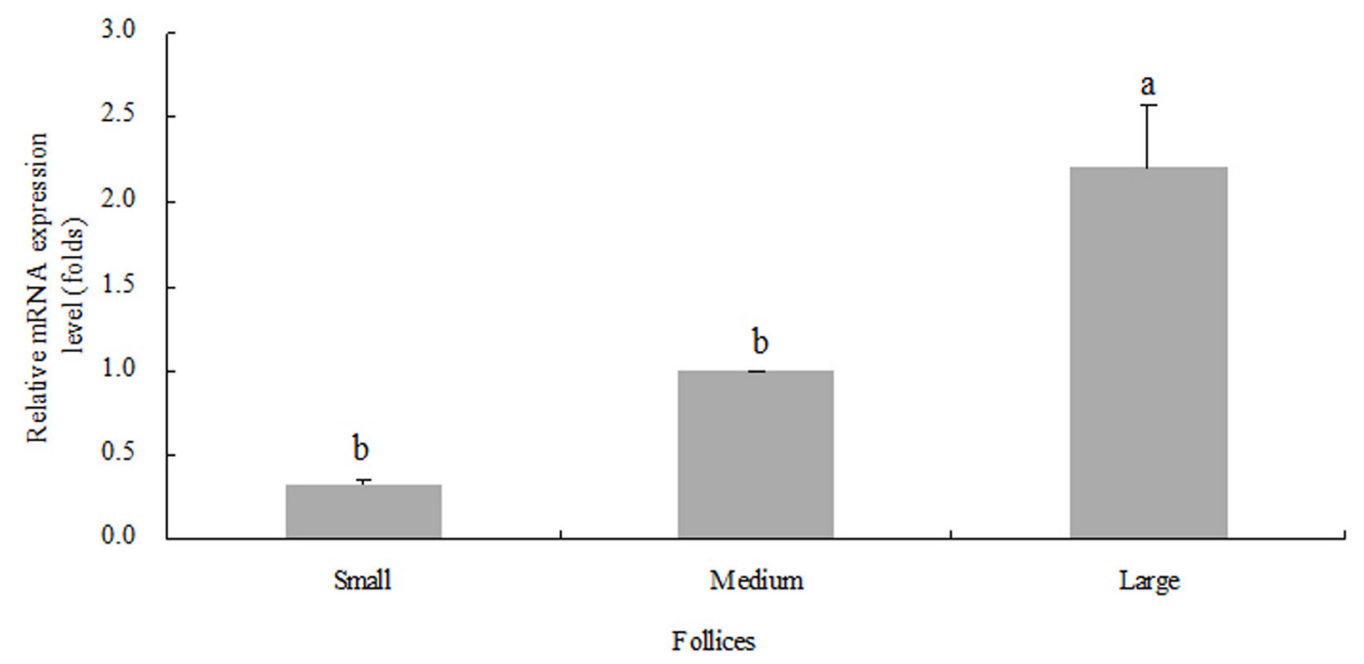

Figure 1. Expression of BMPRIB in follicles of different sizes of commercial pigs. Data are reported as means \pm $\mathrm{SE}$ of three independent experiments, statistically significant differences $(\mathrm{P}<0.05)$ among the groups are indicated by different letters.

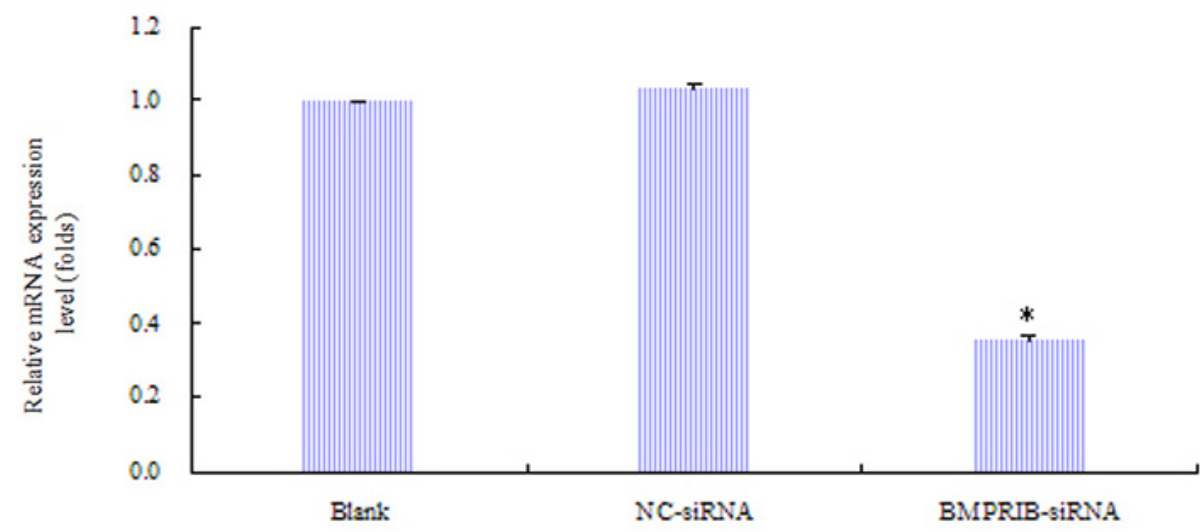

Figure 2. Analyses of the expression of Smad4 mRNA by real-time PCR at post-transfection. Data are reported as means \pm SE of three independent experiments. *Statistically significant differences $(\mathrm{P}<0.05)$ among the groups.

\section{Effects of BMPRIB-siRNA transfection on proliferation of GCs}

MTT analysis was performed to detect the effect of BMPRIB-siRNA transfection on the proliferation of GCs. BMPRIB knockdown significantly inhibited the growth of GCs, as 
compared with the blank and NC-siRNA control $(\mathrm{P}<0.05)$ (Table 3).

\begin{tabular}{lc}
\multicolumn{2}{l}{ Table 3. Effect of endogenous BMPRIB silence on the proliferation of GCs. } \\
\hline Group & OD $_{550}$ \\
\hline Blank control & $0.2197 \pm 0.0027^{\mathrm{a}}$ \\
NC-siRNA & $0.2113 \pm 0.0132^{\mathrm{a}}$ \\
BMPRIB-siRNA & $0.1640 \pm 0.0110^{\mathrm{b}}$ \\
\hline
\end{tabular}

Expression of BMPRIB $48 \mathrm{~h}$ post-transfection. Values are reported as means \pm SE. Statistically significant differences $(\mathrm{P}<0.05)$ among the groups are indicated by different letters.

\section{Effects of BMPRIB siRNA transfection on cell cycle-related genes}

To investigate the mechanism of effects of BMPRIB-siRNA transfection on the proliferation of GCs, we measured the expression of cyclin D2 and Cdk2, which are cell cyclerelated genes, by quantitative real time RT-PCR. We found that cyclin D2 and Cdk2 mRNA levels were decreased, compared with those in the controls $(\mathrm{P}<0.05)$ (Figure 3).

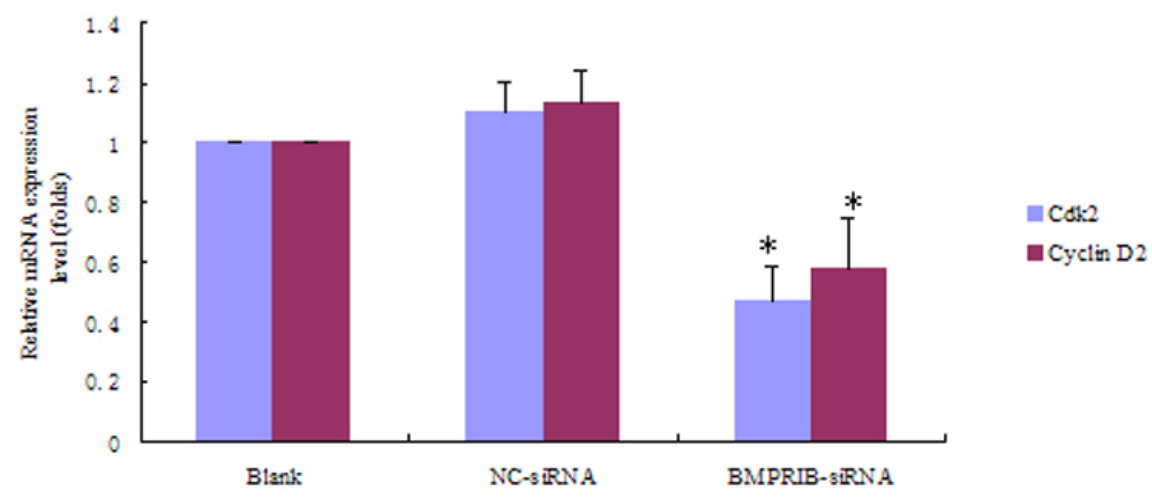

Figure 3. Effects of BMPRIB siRNA transfection on cell cycle-related genes. Data are reported as means $\pm \mathrm{SE}$ of three independent experiments. *Statistically significant differences $(\mathrm{P}<0.05)$ among the groups.

\section{Effects of BMPRIB siRNA transfection on apoptosis of GCs}

Annexin-V/propidium iodide flow cytometry analysis was performed to detect the effects of BMPRIB-siRNA transfection on the apoptosis of GCs. The results in Table 4 and Figure 4a show that BMPRIB knockdown significantly promoted the apoptosis of GCs, as compared with the blank control $(16.85$ vs $10.55 \%$; $\mathrm{P}<0.05)$, whereas there was no significant effect on cell apoptosis of the blank and NC-siRNA control.

\section{Effects of BMPRIB siRNA transfection on cell apoptosis-related genes}

To confirm whether the effects of BMPRIB siRNA transfection on apoptosis of pGCs were involved in the expression changes of cell apoptosis-related genes, the mRNA 
expressions of Bcl-2 and Bax, related markers of cell apoptosis, were measured by quantitative real-time PCR. In BMPRIB knockdown cells, the levels of Bcl-2 mRNA were significantly down-regulated, as compared with blank controls (60.12\%), and down-regulated $54.74 \%$ as compared with NC-siRNA. On the other hand, the levels of Bax mRNA were not significantly changed by BMPRIB knockdown (Figure 4B).

\begin{tabular}{|c|c|c|c|}
\hline Group & Dead cell rate & Apoptotic cell rate & Living cell rate \\
\hline Blank control & $0.55 \pm 0.05^{\mathrm{a}}$ & $10.55 \pm 0.05^{\mathrm{a}}$ & $88.9 \pm 0.00^{\mathrm{a}}$ \\
\hline NC-siRNA & $1.2 \pm 0.50^{\mathrm{a}}$ & $10.35 \pm 1.55^{\mathrm{a}}$ & $88.45 \pm 2.05^{\mathrm{a}}$ \\
\hline BMPRIB-siRNA & $0.4 \pm 0.14^{\mathrm{a}}$ & $16.85 \pm 0.55^{b}$ & $82.7 \pm 0.60^{\mathrm{a}}$ \\
\hline
\end{tabular}

Data are reported as means \pm SE of three independent experiments. Statistically significant differences $(\mathrm{P}<0.05)$ among the groups are indicated by different letters.

(a)

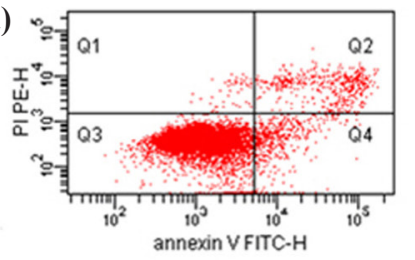

A

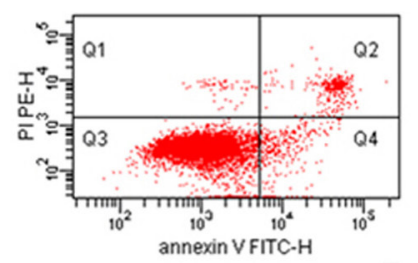

B

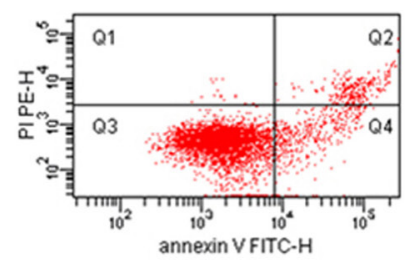

C

(b)

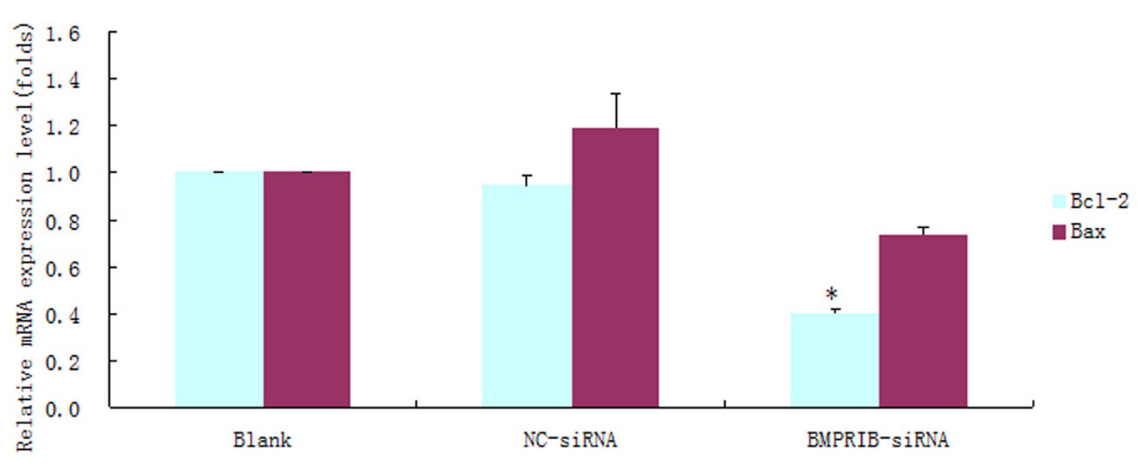

Figure 4. Effect of $B M P R I B$ gene silencing by siRNA on apoptosis of porcine granulosa cells. (a) Relative mRNA expression of apoptosis related genes. (b) Scatter plots of apoptosis with siRNA of GCs. A. blank control; B. negative control; C. BMPRIB-siRNA. Data are reported as means \pm SE of three independent experiments. *Statistically significant differences $(\mathrm{P}<0.05)$ among the groups.

\section{Effects of BMPRIB siRNA transfection on steroidogenic enzyme genes}

To confirm whether the effects of BMPRIB gene silencing by siRNA were involved in the expression changes of steroidogenic enzyme genes, the levels of mRNA encoding Cyp19a1 and Cyp11a1, key enzymes regulating E2 and P4 production in GCs (Lee et al., 2001), were examined by quantitative real-time PCR. The levels of Cyp19a1 mRNA expression were decreased by BMPRIB knockdown (Figure 5). 


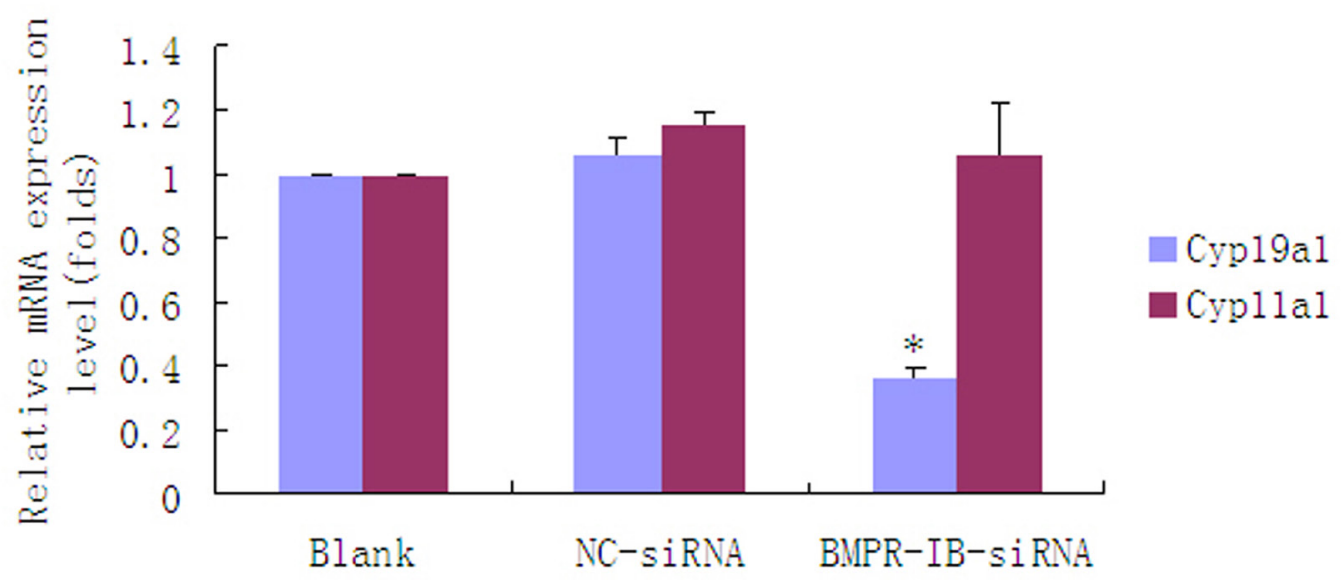

Figure 5. Effects of BMPRIB siRNA transfection on steroidogenic enzyme genes. Data are reported as means $\pm \mathrm{SE}$ of three independent experiments. *Statistically significant differences $(\mathrm{P}<0.05)$ among the groups.

\section{DISCUSSION}

BMP receptors have two subtypes: I and II. Both share structural similarity and possess intrinsic serine/threonine kinase activity. BMPRIB belongs to the type I receptor. Plenty of studies have shown that the expression of BMPRIB was related to productivity in sheep. We found that BMPRIB mRNA levels were significantly higher in Erhualian pigs than in the Pietrain pigs, by quantitative real time RT-PCR, which agrees with high-throughput microarray assay results that the expression of BMPRIB was about 5 times higher in Erhualian than in Pietrain pigs (Jingjing Wang, unpublished results).

To further study whether the expression of BMPRIB was related to the follicular development, we detected the expression of BMPRIB in small, medium, and large follicles. We found that the expression of BMPRIB was significantly higher in large follicles than in small and medium follicles, and tended to increase during porcine follicular development, which was consistent with the result of Paradis et al. (2009). In their study of GCs in porcine follicles, Paradis et al. (2009) found that BMPRIB mRNA was higher in the final selection phase than in the mid selection phase. In the early stages of follicular development in rat, BMPRIB mRNA expression gradually increased through the process of development, and abundant expression was maintained in the tertiary and dominant follicular stages (Erickson and Shimasaki, 2003).

The expression of BMPRIB has been reported in GCs of rats (Shimasaki et al., 1999), sheep (Souza et al., 2002), pigs (Quinn et al., 2004), and cattle (Glister et al., 2004). Zou and Niswander (1996) found that in limb mesenchyme expression of dominant negative, BMPRIB results in the increase of apoptosis. BMPRIB was involved in BMPR-mediated cell death, and caBMPRIB-induced interdigital cell death (Zou et al., 1997), which was consistent with our study. Our results showed that knockdown of endogenous BMPRIB significantly inhibited cell proliferation and promoted cell apoptosis. The proliferative capacity by BMPRIB may reflect a primary role for BMP signaling in regulation of the cell cycle. Alternatively, BMPRIB may affect proliferation by influencing cell adhesiveness or extracellular matrix production (Yi et al., 2000). 
It is known that cell proliferation depends on the cell cycle, and the G1/S and G2/M checkpoints can be seen as master checkpoints of the mammalian cell cycle (Fishman et al., 1998). In mammals, regulation of the G1 phase of the cell cycle involves many different families of the cyclins, D-type cyclins (including cyclins D1, D2, and D3) (Fishman et al., 1998), and Cdks; and Cdk2 plays a crucial role in cell proliferation by regulating DNA synthesis at the beginning of the cell cycle and regulating the cell cycle from the G1 phase to the S phase (Long et al., 2010). Knockdown of BMPRIB inhibits cell proliferation, which may be related to the downregulation of cyclin D2 and Cdk2, both being downstream molecules of BMP signaling. The decreased expression of BMPRIB leads to the blocking of the BMP-induced signaling pathway.

At least four cell death systems (Bcl-2 family, tumor necrosis factor, TGF- $\beta$, and Fas/FasL) have been reported so far in granulosa cells of ovaries in the process of follicular development. The Bcl-2/Bax ratio also regulates apoptosis of primordial follicles (Hussein, 2005). We found that knockdown of BMPRIB promoted apoptosis, with the significant downregulation of Bcl-2 expression and without significant changes of Bax expression; this is consistent with the study by Lagna et al. (2006), in which they found that in pulmonary artery smooth muscle cells, BMP-induced apoptosis was mainly dependent on mitochondrial dysfunction and led to the expression of Bcl-2 downregulation. In primary osteoblasts, BMP-2 induced apoptosis in a Smad-dependent manner (Hay et al., 2001). In addition, the apoptosis of pGCs was thought to be regulated by a mitochondrion-dependent apoptosis-signaling pathway (Manabe et al., 2004). Zou et al. (1997) found that activated BMPRIB provoked apoptosis, and the apoptotic pathway was triggered mainly by BMPRIB-meditated signal transduction. Kim et al. (1998) found that the apoptosis of granulosa cells may be related to the upregulated expressions of Fas and FasL at the penultimate stage of rat follicular development. In addition, Fas and FasL were expressed in healthy, early atretic and progressively atretic porcine follicles (Lin and Rui, 2010). The reduced expression of endogenous BMPRIB may indirectly result in the downregulation of $\mathrm{Bcl}-2$, thereby promoting the apoptosis of granulosa cells. However, further studies are required to prove whether it is connected with Fas and FasL.

\section{ACKNOWLEDGMENTS}

Research supported by the Hi-Tech Research \& Development program of China (\#2006AA10Z136).

\section{REFERENCES}

Brankin V, Quinn RL, Webb R and Hunter MG (2005). BMP-2 and -6 modulate porcine theca cell function alone and co-cultured with granulosa cells. Domest. Anim. Endocrinol. 29: 593-604.

Edson MA, Nalam RL, Clementi C, Franco HL, et al. (2010). Granulosa cell-expressed BMPR1A and BMPR1B have unique functions in regulating fertility but act redundantly to suppress ovarian tumor development. Mol. Endocrinol. 24: 1251-1266.

Erickson GF and Shimasaki S (2003). The spatiotemporal expression pattern of the bone morphogenetic protein family in rat ovary cell types during the estrous cycle. Reprod. Biol. Endocrinol. 1: 9.

Fishman DD, Segal S and Livneh E (1998). The role of protein kinase C in G1 and G2/M phases of the cell cycle (review). Int. J. Oncol. 12: 181-186.

Glister C, Kemp CF and Knight PG (2004). Bone morphogenetic protein (BMP) ligands and receptors in bovine ovarian follicle cells: actions of BMP-4, -6 and -7 on granulosa cells and differential modulation of Smad-1 phosphorylation 
by follistatin. Reproduction 127: 239-254.

Hay E, Lemonnier J, Fromigue O and Marie PJ (2001). Bone morphogenetic protein-2 promotes osteoblast apoptosis through a Smad-independent, protein kinase C-dependent signaling pathway. J. Biol. Chem. 276: 29028-29036.

Heldin CH, Miyazono K and ten Dijke P (1997). TGF- $\beta$ signalling from cell membrane to nucleus through SMAD proteins. Nature 390: 465-471.

Hussein MR (2005). Apoptosis in the ovary: molecular mechanisms. Hum. Reprod. Update 11: 162-177.

Kim JM, Boone DL, Auyeung A and Tsang BK (1998). Granulosa cell apoptosis induced at the penultimate stage of follicular development is associated with increased levels of Fas and Fas ligand in the rat ovary. Biol. Reprod. 58: 1170-1176.

Lagna G, Nguyen PH, Ni W and Hata A (2006). BMP-dependent activation of caspase-9 and caspase-8 mediates apoptosis in pulmonary artery smooth muscle cells. Am. J. Physiol. Lung Cell Mol. Physiol. 291: L1059-L1067.

Lavery K, Swain P, Falb D and Alaoui-Ismaili MH (2008). BMP-2/4 and BMP-6/7 differentially utilize cell surface receptors to induce osteoblastic differentiation of human bone marrow-derived mesenchymal stem cells. J. Biol. Chem. 283: 20948-20958.

Lee WS, Otsuka F, Moore RK and Shimasaki S (2001). Effect of bone morphogenetic protein-7 on folliculogenesis and ovulation in the rat. Biol. Reprod. 65: 994-999.

Lin P and Rui R (2010). Effects of follicular size and FSH on granulosa cell apoptosis and atresia in porcine antral follicles. Mol. Reprod. Dev. 77: 670-678.

Livak KJ and Schmittgen TD (2001). Analysis of relative gene expression data using real-time quantitative PCR and the 2(-Delta Delta C(T)) Method. Methods 25: 402-408.

Long XE, Gong ZH, Pan L, Zhong ZW, et al. (2010). Suppression of CDK2 expression by siRNA induces cell cycle arrest and cell proliferation inhibition in human cancer cells. BMB. Rep. 43: 291-296.

Manabe N, Goto Y, Matsuda-Minehata F, Inoue N, et al. (2004). Regulation mechanism of selective atresia in porcine follicles: regulation of granulosa cell apoptosis during atresia. J. Reprod. Dev. 50: 493-514.

Miyoshi T, Otsuka F, Suzuki J, Takeda M, et al. (2006). Mutual regulation of follicle-stimulating hormone signaling and bone morphogenetic protein system in human granulosa cells. Biol. Reprod. 74: 1073-1082.

Nilsson EE and Skinner MK (2003). Bone morphogenetic protein-4 acts as an ovarian follicle survival factor and promotes primordial follicle development. Biol. Reprod. 69: 1265-1272.

Otsuka F, Moore RK and Shimasaki S (2001a). Biological function and cellular mechanism of bone morphogenetic protein-6 in the ovary. J. Biol. Chem. 276: 32889-32895.

Otsuka F, Yamamoto S, Erickson GF and Shimasaki S (2001b). Bone morphogenetic protein-15 inhibits folliclestimulating hormone (FSH) action by suppressing FSH receptor expression. J. Biol. Chem. 276: 11387-11392.

Paradis F, Novak S, Murdoch GK, Dyck MK, et al. (2009). Temporal regulation of BMP2, BMP6, BMP15, GDF9, BMPR1A, BMPR1B, BMPR2 and TGFBR1 mRNA expression in the oocyte, granulosa and theca cells of developing preovulatory follicles in the pig. Reproduction 138: 115-129.

Picton HM, Campbell BK and Hunter MG (1999). Maintenance of oestradiol production and expression of cytochrome P450 aromatase enzyme mRNA in long-term serum-free cultures of pig granulosa cells. J. Reprod. Fertil. 115: 67-77.

Quinn RL, Shuttleworth G and Hunter MG (2004). Immunohistochemical localization of the bone morphogenetic protein receptors in the porcine ovary. J. Anat. 205: 15-23.

Shi Y and Massague J (2003). Mechanisms of TGF-beta signaling from cell membrane to the nucleus. Cell 113: 685-700.

Shimasaki S, Zachow RJ, Li D, Kim H, et al. (1999). A functional bone morphogenetic protein system in the ovary. Proc. Natl. Acad. Sci. U. S. A. 96: 7282-7287.

Shimasaki S, Moore RK, Erickson GF and Otsuka F (2003). The role of bone morphogenetic proteins in ovarian function. Reprod. Suppl. 61: 323-337.

Shimasaki S, Moore RK, Otsuka F and Erickson GF (2004). The bone morphogenetic protein system in mammalian reproduction. Endocr. Rev. 25: 72-101.

Souza CJ, MacDougall C, MacDougall C, Campbell BK, et al. (2001). The Booroola (FecB) phenotype is associated with a mutation in the bone morphogenetic receptor type 1 B (BMPR1B) gene. J. Endocrinol. 169: R1-R6.

Souza CJ, Campbell BK, McNeilly AS and Baird DT (2002). Effect of bone morphogenetic protein 2 (BMP2) on oestradiol and inhibin A production by sheep granulosa cells, and localization of BMP receptors in the ovary by immunohistochemistry. Reproduction 123: 363-369.

Wilson T, Wu XY, Juengel JL, Ross IK, et al. (2001). Highly prolific Booroola sheep have a mutation in the intracellular kinase domain of bone morphogenetic protein IB receptor (ALK-6) that is expressed in both oocytes and granulosa cells. Biol. Reprod. 64: 1225-1235.

Yi SE, Daluiski A, Pederson R, Rosen V, et al. (2000). The type I BMP receptor BMPRIB is required for chondrogenesis in the mouse limb. Development 127: 621-630. 
Zou H and Niswander L (1996). Requirement for BMP signaling in interdigital apoptosis and scale formation. Science 272: 738-741.

Zou H, Wieser R, Massague J and Niswander L (1997). Distinct roles of type I bone morphogenetic protein receptors in the formation and differentiation of cartilage. Genes Dev. 11: 2191-2203. 